Letrônica, Porto Alegre, v. 7, n. 2, p. 1029-1042, jul./dez., 2014

\title{
OLHANDO PARA TRÁS E EM FRENTE: PERSPECTIVAS DE VIAGENS EM TUTAMEIA TERCEIRAS ESTÓRIAS, DE JOÃO GUIMARÃES ROSA
}

\author{
LOOCKING BACK AND FORWARD: \\ TRIP PERSPECTIVES IN TUTAMEIA TERCEIRAS ESTÓRIAS, \\ BY JOÃO GUIMARÃES ROSA
}

\author{
Regina da Costa da Silveira* \\ Fábio Antônio Dias Leal**
}

\begin{abstract}
Resumo: Ir e vir é um direito assegurado a todo cidadão. Deslocar-se é próprio da espécie animal; escolher caminhos, traçar uma via para viajar, é característica humana. 0 artigo pretende identificar, no itinerário de personagens do livro Tutameia Terceiras Estórias, os motivos que os impulsionam para viajar, bem como observar o traçado espacial desse itinerário. Ocorre que entre esses personagens a viagem torna-se diversa em sua configuração, à medida que não são apenas viagens por estradas reais, por terra e por rio, por meio de montaria ou de barco. 0 tema da viagem em Tutameia configura-se também pela metáfora do olhar para frente e para trás, o que se reverte na ação do próprio leitor na travessia de ir e vir, direito e dever assegurados por um narrador. Propõe-se uma análise intratextual da obra rosiana, para interpretar enigmas que se imbricam entre personagens de contos diferentes, na representação metafórica da viagem. Palavras-chave: Viagem; Tutameia Terceiras Estórias; Intertextualidade.
\end{abstract}

\begin{abstract}
Coming and going is a right guaranteed to every citizen. Moving around is characteristic of the animal species; choosing paths, tracing a route to travel, is a human characteristic. The article aims to identify, in the itinerary of the characters in the book Tutameia Terceiras Estórias, the motives that push them on to travel, as well as to observe the spatial trace of that route. It occurs that among these characters the journey becomes diverse in its configuration, as they are not only real road trips, by land and river, by horseback riding or boating. The theme of the Tutameia trip is also onfigured by the metaphor of looking forward and backward, which reverses the action of the readers themselves in crossing back and forth, a right to and duty to assured by a narrator. We suggest an intratextual analysis of the work of Rosa, interpreting riddles that intertwine between characters from different stories, in the metaphorical representation of the trip.

Keywords: Travel; Tutameia Terceiras Estórias; Intertextuality.
\end{abstract}

\footnotetext{
* Regina da Costa da Silveira - Doutorado em Letras UFRGS; Professora Titular do PPG Letras UniRitter; Editora de Nonada Letras em Revista. E-mail: regina silveira@uniritter.edu.br

** Fábio Antônio Dias Leal- Pós-graduação em Assessoria Linguística Produção e Revisão Textual UniRitter; Mestrado em curso no PPG Letras UniRitter. E-mail: fabiodleal@bol.com.br
} 


\section{Introdução}

Para tratar da viagem, tema tão caro a João Guimarães Rosa, imperioso torna-se ler, repetidas vezes, a obra Tutameia Terceiras Estórias (1994) - publicada em junho de 1967, ano do falecimento do autor - no intuito de encontrar a cada linha algo inusitado na obra de quarenta narrativas curtas e de quatro insólitos prefácios. Para uma revisão conceitual, interessante é lembrar que o termo "tutameia" assume vários significados, querendo dizer "tuta-e-meia, ninharia, quase-nada, preço vil, pouco dinheiro"; e mais: "nonada, baga, ninha, inânias, ossos de borboleta, quiquiriqui, mexinflório, chorumela, nica". Paulo Rónai publicou esses significados no jornal O Estado de São Paulo, em 1968, mas sabe-se que todos eles foram antes atribuídos pelo próprio Rosa ao seu último livro publicado em vida.

Propõe-se uma análise intratextual da obra rosiana, para interpretar enigmas que se imbricam entre personagens de contos em diferentes obras, na representação metafórica da viagem, lembrando de modo especial os múltiplos sentidos da palavra travessia, o mundo movente de Guimarães Rosa, expressão que intitula a obra, que trata de Grande Sertão: Veredas, de José Carlos Garbuglio, aporte de referência crítica neste artigo.

\section{Doriano: um almirante em mar secado}

O conto "Sota e barla" narra a história do vaqueiro Doriano, "de gibão e jaleco, de repartido olhar", que conduzia à fazenda Capiabas, de seu patrão, Seo Siqueira-assú, uma comitiva formada por "vaqueiros lorpas patifes e semi-selvagens bois" (ROSA, 1994, p. 689)"1. O desenvolvimento da narrativa permite ao leitor traçar um panorama do universo íntimo de Doriano ao longo da viagem; conhecem-se os seus rivais, o vaqueiro Rulimão, "desordeiro, de por-lhe abrolhos, e o três vezes rival, desamigo", Drujo, que, ao mesmo tempo, conduzia outra boiada, também de Seo Siqueira-assú, com destino à mesma fazenda, "Os homens de confiança" do vaqueiro também são relacionados: o cozinheiro Duque e o esteira Seistavado, "dos tristonhos".

\footnotetext{
${ }^{1}$ Todas as notas seguintes referem-se à publicação de Tutameia Terceiras Estórias, Volume II, de Ficção Completa, Editora Nova Aguilar, ao qual nos referiremos, a partir daqui, somente pelas páginas. Os grifos são nossos.
} 
A primeira aflição de Doriano consiste na iminência de seu rival chegar primeiro com a boiada ao destino previsto. A segunda é da ordem dos sentimentos, "de amores contrários, que esperavam seu resolver" (p. 689), entre a Aquina e a Bici, que moravam rumo-a-rumo, ainda longe dali, os dois amores de Doriano. A terceira aflição do vaqueiro configura um problema de viagem: faltava água, uma vez que encontraram "secadas as esperadas grotas". A viagem torna-se tensa; o gado está sob risco; os vaqueiros, insatisfeitos, murmuram contra Doriano; o rebelde Rulimão mostra-se ainda mais insolente. $\mathrm{O}$ condutor da boiada sobe a um monte, na tentativa de visualizar a posição de Drujo, e considera sua possível vantagem, mas compreende que não pode sobrepor sua pressa ao tempo próprio dos vaqueiros, não pode impor urgência ao passo natural dos bois. Segue seu caminho, encontra água, afinal, e arrefecem os ânimos dos vaqueiros.

Aliviado com a descoberta de água, Doriano pode voltar a divagar sobre os seus amores. Já próximo de seu destino, encontra-se banda a banda com a morada de suas musas, Aquina e Bici. Em uma decisão surpreendente, envia o rebelde Rulimão com dinheiro à Aquina, a quem também deveria proteger de "qualquer vindiço"; à Bici envia seu homem de confiança, o esteira Seistavado, com votos de casamento. Chega então à fazenda Capiabas antes de seu rival Drujo lá chegar; o gado sem danos; de seu amor, "a Bici, branquinha flor, tendo a perfeita certeza" (p. 691).

Em sua obra As três Graças, Heloisa Vilhena de Araújo (2001) destaca a recorrência em "Sota e barla" a termos náuticos, o que justifica a expressão "marinheiro em mar secado":

\footnotetext{
O conto "Sota e barla" trata, como o título indica, dos dois lados de um navio em viagem: sotavento (de onde sopra o vento) e barlavento (para onde sopra o vento). A favor do vento ou contra o vento.

E Doriano, vaqueiro, navegava com a boiada, que deveria levar à fazenda do patrão e dono, Seo Siqueira-assú, Fazenda Capiabas. O sotavento estava à esquerda [...]. De acordo com o título do conto, Guimarães Rosa continua empregando termos náuticos e ligados ao mar: 'marinheiro', 'abrolhos', 'navegando' (p. 262-263).
}

Também são recorrentes as referências à dualidade ou, mais especificamente, à bilateralidade, no conto:

Feio é, todo modo, passar-se do sertão uma boiada, estorvos e perigos, dos dois lados, por espaço de setenta léguas.

Doriano, de gibão e jaleco, havendo de repartido olhar [...]. 
Dali ainda a longe, etapas, rumo-a-rumo, ao vice e versa da estrada, viviam aquelas em que Doriano cuidava [...]. as duas, amores contrários que a esperarem seu resolver. A Aquina e a Bici. Doriano, chefe, perrengue trotava, $a$ de-cá a de-lá [...]. Espiou o poente: nem nada. Erguido firmado nos estrivos, espiou o nascente. [...] Aquina, ociosa meretriz, na Caçapa, banda da mão direita. A Bici, moça para ser noiva, à beira da lagoa Itãs, do lado do outro lado. (p. 689-690).

No entanto, parece ainda não haver sido notada a súbita interrupção do uso de termos náuticos. De forma direta nos prefácios que compõem a obra, e de forma indireta no enredo dos contos, Guimarães Rosa trata do mundo como vontade e representação, menciona Platão e o mito da caverna; vale-se do pensamento de mundo sensível e de mundo inteligível².

Com efeito, os termos náuticos cessam quando Doriano depara-se com problemas de ordem prática, com a inexorabilidade do mundo material: faltava água. Ganham lugar as recorrentes menções à poeira, consequência de uma viagem via estradas de chão, que assim passa a ser ricamente adjetivada:

Rixavam já os vaqueiros, queixosos, grossa, parda de poeira cada cara, só fora os vermelhos beiços. 0 gado berrava. Doriano, chefe, perrengue trotava, a de-cá a de-lá e da guia à culatra, nessa confusão e labirinto, sem certeza do melhor e pior. (p. 690).

Seria o nono dia de viagem o dia da dissipação das ilusões de Doriano? A experiência da falta d'água insere o vaqueiro na materialidade do mundo. A poeira é relacionada agora com requinte:

[...] grossa, parda de poeira cada cara, só fora os vermelhos beiços. Entupia-o o constipado, apertada a testa [...]. Por cima de cerradão, se enxergava bolo de poeira, suspendida, que o vento rebate e desairada se esfaz. Tossisse, a barba grada, no empoeiramento, condenado nisso, mais uns vaqueiros esfalfados. (p. 690-691).

Curiosa é a constatação de que a última ocorrência é a da chegada da comitiva a seu destino, portanto, muito depois de ter sido solucionado o problema da falta d'água. Podemos considerar que Doriano, que se encontrava "sem certeza do melhor e pior", compreende-se então "condenado nisso" (p. 691), condenado à poeira, representação do mundo material que, por sua vez, remete metaforicamente ao mundo inteligível. 0

\footnotetext{
${ }^{2}$ Araújo (2001) destaca a importância da obra de Schopenhauer para a constituição de Tutaméia Terceiras Estórias. A incidência de duas epígrafes de Schopenhauer, que orientam a leitura e a releitura da obra, reforça a concepção da autora. No entanto, não é propósito deste ensaio discorrer sobre o pensamento filosófico de Platão e de Schopenhauer.
} 
vaqueiro adquire uma nova apreensão da realidade para, ao fim do conto, apresentar-se “Tendo a perfeita certeza” (p. 691).

Destacamos então fortes indícios intratextuais na obra de Rosa, elementos de diferentes contos que, não obstante apontem às vezes para direções contrárias, encontram entre si correspondência que em muito nos auxilia na construção de novos sentidos, no desvendar dos enigmas dessas narrativas. No caso do conto "Intruge-se", a intratextualidade se estabelece à medida que se lê o conto "A Estória do Homem do Pinguelo", quarta narrativa da obra póstuma Estas Estórias, que faz referência a um condutor de bois pouco comum, como adiante se observa:

Decerto, vira-se o condutor dos bois forçado a deixar a grande rota cumeeira, sem pastos, falha de águas. Optara, daí, por um itinerário de fortuna, a seguir, o mais possível, o ribeirão, onde resta sempre, aqui ou ali, alguma vegetação marginal, embora escassa. Seja, de qualquer modo, que estaria o boiadeiro ante todos os problemas - almirante em mar secado, com suas favas mal contadas, aprendiz do que não quis... (ROSA, 1994, p. 810).

Não atribuiríamos tanta importância à relação possível entre Doriano e o vaqueiro almirante de "A Estória do Homem do Pinguelo", não fosse a coincidência inscrita em um âmbito mais amplo: Doriano não é o único personagem identificado na lista de problemas de boiadeiros, do conto de Estas Estórias. No enigmático conto "Intruge-se", uma das mais herméticas narrativas de Tutameia Terceiras Estórias, o vaqueiro Ladislau também se encontra em apuros quando conduzia a boiada de seu patrão Drães, dos gerais do Saririnhém para a fazenda do dono. Na madrugada do terceiro dia de viagem, um dos homens da comitiva é assassinado; não se sabe qual dos boiadeiros é o criminoso. Ladislau terá que prestar contas do ocorrido ao patrão; seu misterioso cachorro amarelo, Eu-Meu, não latiu na hora do crime; Ladislau, portanto, sabe-se suspeito. Para solucionar o caso, o condutor da boiada vale-se de um método insólito: apanha oito vagens pequenas de jubaí; cutuca as mãos dos vaqueiros repetindo sempre uma mesma pergunta sobre a suposta aquisição da Fazenda da Gralha por seu patrão Drães; avalia os homens da comitiva, faz especulações; descarta as vagens à beira da estrada.

O problema central do conto "Intruge-se", no entanto, parece mesmo ser a contagem dos homens da comitiva de Ladislau. "Onze homens tangiam-nos", diz o narrador, para em seguida relacionar treze nomes, dentre os quais não sabemos sequer 
se o narrador se inclui. A exclusão do cozinheiro - que normalmente andava à frente da boiada - e a hipótese de que "Piorra" seja apenas um apelido do vaqueiro "Liocádio"3 são indícios que parecem resolver o problema da contagem dos homens. No entanto, um leitor mais atento perceberá que Ladislau gasta uma vagem para o "Liocádio" e outra para o "Piorra", o que, supostamente, invalidaria a hipótese. Arriscamo-nos a pensar que seja o narrador de "A Estória do Homem do Pinguelo" quem esclarece a questão ao mencionar um boiadeiro com suas favas mal contadas.

\section{Travessia de banda a banda: intratextualidades e símbolos}

Com efeito, o boiadeiro/almirante em "mar secado", protagonista de "Sota e barla", não está sozinho em sua viagem entre as narrativas curtas de Tutameia Terceiras Estórias. Em "Azo de Almirante", quarta narrativa do livro, o almirante Hetério é quem rege as canoas junto aos filhos que "Iam rumo ao Calcanhar" onde "se preparava uma desordem". Nesse conto, o motivo da viagem junto ao rio vem expresso já a partir do título: a palavra "azo" significa motivo, ensejo, pretexto e ocasião; "almirante", conforme a hierarquia militar, é título honorífico, cargo de quem ocupa o primeiro posto na Marinha de Guerra. Ao descrever a paisagem, renova-se nesse conto o recurso de repetição, característica da contística rosiana. A descrição das canoas "em celeuma", alarido de cantoria e vozerio dos canoeiros, demonstra ordenação, brilho e movimento:

\footnotetext{
Longe, atrás uma da outra, passaram as mais que meia dúzia de canoas enchusmadas e em celeuma, ao empuxo dos remos, a toda a voga. 0 sol a tombar, o rio brilhando que qual enxada nova, destacavam-se as cabeças no resplandecer. Iam rumo ao calcanhar, aonde se preparava alguma desordem. (p. 539).
}

O vocabulário em "Azo de Almirante" remete também ao campo semântico da navegação, a começar pelo verbo vogar que significa navegar com auxílio dos remos. 0 narrador conduz o interlocutor/leitor para uma dinâmica de leitura em que o olhar quase simultâneo "para trás e em frente" torna-se imperioso para a compreensão da trama. Nessa conjunção de opostos, verifica-se o duplo aspecto que empolga e perturba o leitor, o que Garbuglio (1972, p. 53), ao examinar o romance Grande Sertão: Veredas,

\footnotetext{
3 "Liocádio, o Piorra, Joãozão e Amazono, revezados, abriam cova, com demora, por falta de boa ferramenta" (p. 589) - o uso do artigo definido, somente para a referência ao Piorra, denuncia um aposto que, ao leitor menos avisado, pode passar despercebido.
} 
de Guimarães Rosa, denominou "vertigem do redemoinho", situação em que o redemoinho parece tragar o personagem/narrador. No caso de "Azo de Almirante", o leitor é tragado pelo narrador, como se o olhar do leitor devesse compulsoriamente voltar-se para trás, a história vai sendo narrada a partir do passado, mas, de vez em quando e de modo abrupto, retorna-se ao presente por indicação do narrador.

Nesse movimento de ir e vir, o leitor depara-se com os fatos passados, introduzidos pela expressão que os sintetiza como: “Eventos vários” (p. 539). Retorna-se então - pela primeira vez - à imagem inicial e ao presente: “Agora, ao por-do-sol, desciam as canoas" (p. 540). Mas o olhar para trás outra vez é necessário e, nesse intento, cabe ao narrador sofrear a viagem do leitor conduzindo-o no fluxo da narrativa com o uso da expressão que constitui um único parágrafo: “Ainda não.” E para que se dê a continuidade, é indispensável uma mirada para trás: "Seguindo-se antes outros atos". (p. 540). Sabe-se, afinal, de uma desordem na Fazenda-do-Calcanhar para onde o canoeiro se desloca. Observa-se, então, a repetição no texto, com a retomada da descrição inicial da paisagem e a inserção das canoas:

\footnotetext{
Assim ao longe, contra raso sol, viu-se a fila de canoas, reta rápida, remadas no brilhar, como homens com armas, de Normão, que rumavam a rixa e foto. Hetério comandava-as, definitivo severamente decerto, sua figura apropriada, vogavagante. (ROSA, 1994, p. 540).
}

Nessa trama, conforme se lê, Hetério obteve sucesso devido à enchente, pois muitas pessoas foram salvas por ele. Ao que tudo indica, a catástrofe, representada pela calamidade da enchente, é o que propicia “ocasião de herói” (p. 540) ao canoeiro, ainda que, de início, "Não o suspeitavam inclinado ao êxito do século." (p. 539).

Em Tutameia Terceiras Estórias, o tema da viagem se expressa já no primeiro conto, "Antiperipleia", quando o protagonista, guia de cego, anuncia ao interlocutor: “- E o senhor quer me levar, distante, às cidades? Delongo. Tudo, para mim, é viagem de volta." (p. 527). Valendo-se, portanto, do olhar em direção ao passado, o guia confessa ter "culpas retapadas" pela queda do cego no precipício. Para comparar sua antiperipleia à navegação, declara o guia: "A gente na rua, puxando cego, concerne que nem se avançar navegando - ao contrário de todos." (p. 527). Ao final do conto, decide-se, porém, o narrador por aceitar ir adiante, seguir, "bem-procedidamente, no de-vagar de ir longe. Voltar, para fim de ida. [...] Vou [...] vagavaz, habitual no diferente, com o senhor, 
Seô Desconhecido" (p. 529). Vale anotar ainda a expressão "Voltar, para fim de ida.", associada aqui ao "olhar para frente e atrás", do conto "Sota e barla", quando o guia afirma: "Repenso, não penso."

Ao que tudo indica, o Seô Desconhecido pode representar a figura do leitor em sua possível cegueira diante da construção de uma narrativa em que a repetição se faz, por conta mesmo da cegueira, muito necessária. Nesse intento, o narrador, guia de cego, ainda pergunta: “A culpa cai sempre é no guiador?” (ROSA, p. 529). Soma-se aqui o provérbio: "Cego suplica de ver mais do que quem vê", com o sentido que pode aludir ao leitor, no papel de crítico literário. Comparado ao cego, o leitor ou o crítico pode ser visto no intuito de "re-criar" o texto, de tentar "ver mais do que quem vê", ou seja, mais do que o guia, no caso, o próprio narrador.

Importante notar que o verbo "reger", no conto "Antiperipleia", é o que confere ideia de superioridade ao guia em relação ao cego por ele conduzido; em "Azo de Almirante", Hetério é o regedor, almirante que comanda a fila de canoas, "reta rápida", o que lembra o bordão que rege o andar do cego pela mão do guia. Lembra, com efeito, a máxima que compõe o perfil desse personagem: "O gênio é o punhal de que não se vê o cabo" (ROSA, p. 539). Garbuglio (1972, p. 54) percebeu as repetições em Grande Sertão: Veredas como "certas informações, reiteradas com insistência". Essas informações marcariam, segundo ele, "polos" ou "unidades funcionais", ao mesmo tempo em que "abrem espaço à compreensão dos significados simbólicos”. Dentre os símbolos que permeiam o conto "Azo de Almirante", encontra-se o espaço sacralizado pelas águas, ora calmas e límpidas, ora barrentas e em torvelinhos. Trata-se da simbologia das águas que é também lembrada oportunamente pelo autor de $O$ mundo movente em Guimarães Rosa (1970), com a recorrência a Mircea Eliade em seu tratado sobre as religiões.

Na trajetória de Hetério, antes do "fatal ano da graça", conforme o texto, ele fora "homem de família, merecedor de silêncio, só no fastio de viver, sem hálito nem bafo", ou seja, homem comum. Com a enchente, Hetério "sobressaíra", enquanto os outros "Não o suspeitavam inclinado ou apontado ao êxito do século". É quando o herói, prestando socorro, salva muita gente da fúria das águas. Para lembrar o duplo aspecto das coisas, e as águas em seu duplo significado implicam tanto o nascimento quanto a morte: ao voltar para casa, Hetério não mais encontra a casa nem os corpos da mulher e das filhas, “que o rio levara" (p. 540). 
Para o narrador, à diferença de Hetério, como homem comum que ficara para trás, o rumo para frente é caracterizado pelo sucesso do canoeiro, e pode ser visto como "aquela novidade de caráter", "jeito de chefe", "ímpetos", "coisa que parecia glória". Mediante a culpa e o sofrimento, Hetério então "não se pareceu mais com ninguém", "Sacudia, com a cabeça, o perplexo existir, de dó sem parar, em tanta maneira" (p. 539). De suas culpas também retapadas, segue-se um olhar direcionado para a frente e "De modo ou de outro, já estava ele adquirindo as boas canoas, de que precisava", e quando a ponte da Fôa foi destruída, o barqueiro transpõe gente de um lado para outro do rio.

Nessa prospecção do herói, entendida como uma mirada de olhos lançada ao futuro, olhar adiante, a travessia de Hetério, feita sempre em uma canoa, evoca o símbolo da barca, "da viagem, de uma travessia realizada seja pelos vivos, seja pelos mortos", conforme Chevalier (1995):

\begin{abstract}
A vida presente também é uma navegação perigosa. Deste ponto de vista, a imagem da barca é um símbolo de segurança. Favorece a travessia da existência, como das existências. Geralmente, uma auréola em forma de barca figura por detrás do personagem de Amida nas representações japonesas; faz lembrar aos fiéis que Amida é um barqueiro-passador, e que sua compaixão os conduzirá além do Oceano das dores, que são a vida neste mundo e o apego a esta vida. Talvez esse personagem budista fosse ele um barqueiro da felicidade. (p. 121-122).
\end{abstract}

De início, o barqueiro Hetério ficou famoso por motivo ou "azo" da enchente; depois, conduziu

Até cortejo de noivos [...], sob baldaquim, até enterros, o bispo em pastoral, troços de soldados. Foi tudo justo. Obedeciam os outros a Hetério - o em posição personificada - o na maior, canoa barcaçosa, a caravela com caveiras (p. 539).

Seu nome lembra a palavra heteria, sociedade política secreta, na Grécia antiga, hoje sociedade também literária grega. Em sua azáfama diária, Hetério "ao certo nada explicava teve de acostumar-se a diferentes situações"; homem "de humor benigno", "cabeça perpétua", um perfil que remete agora ao passado do navegador, mas como "homem merecedor de silêncio", consolidado pela expressão proverbial que diz: “cerrando bem a boca é que a gente se convence a si mesmo" (p. 539). 
Quando a construção da ponte termina, Hetério descobre a existência de uma mulher milagreira, jejuadora rio acima: "Travessavam, com acuração, os peregrinos da santa, aleijados, cegos, doentes de toda loucura e lepra, o rico triste e o pobre precisado." (p. 540). Retomada a travessia, sugerida pelo verbo "Travessavam", na viagem de volta ao passado, constam memórias de herói, mas também de um "Semi-ator", que tem "em mãos o rosário e o remo", "tivesse mudado talvez a lembrança da enchente e de sua ocasião de herói, que era apenas virtude sem fama, um fragmento de lenda". A situação agrava-se para o canoeiro, quando um filho vai morar longe e outro é baleado na briga para ajudar Normão a raptar a mulher. Trata-se da catábase, descida ao mundo subterrâneo ou queda, de Hetério, quando, na canoa, ele

\footnotetext{
estava ferido, não a conduzia de por si, vogavagante; e seu outro filho, na briga terminara, baleado. Adiante, no travessão do fervor, itaipava perigosa, a canoa fez rombo numa "itaipava perigosa" e ele ainda alcança "o brejo da beira, onde atolado se aquietou semi-ator. Acharam-no - risonho morto, muito velho, velhaco - a qualidade de sua pessoa (p. 541).
}

A propósito do nome do lugar - Fazenda-do-Calcanhar -, para onde as canoas desciam no início da viagem, sabe-se que é o lugar onde Normão, "homem apaixonado, na maior imaginação" (p. 541), tem de reaver a mulher, guardada pelo pai como refém; justo nesse lugar morre Hetério, "devolvido ao barro".

Chevalier registra que à hora da morte, segundo uma crença Semang, a alma deixa o corpo pelo calcanhar. Lembra que Aquiles era vulnerável no calcanhar por motivo da propensão à violência e à cólera que são fraquezas da alma - e o pé é símbolo da alma: quando atingido, o homem cai. “O calcanhar é como a base do ser humano. [...] Para a lógica imaginativa não parece nem um pouco contraditório que seja por ali que a vida ou a alma escapem e também por ali entre a morte" (CHEVALIER, 1995, p. 165). Em "Azo de Almirante", Hetério e os seus revelam-se violentos, quando "Aproaram aos fundos da do-Calcanhar, numa gamboa, a atacaram, de faca em polpa" e, então, "As canoas todas entanto se perderam" (p. 541). Quanto ao nome do protagonista, antes aqui lembrado em sua origem grega, cabe acrescentar que o verbo "eterizar", sem a letra "h" inicial, significa desfazer, evaporar-se, remete também a etéreo, sublime, puro e elevado.

Para lembrar o duplo sentido das coisas em Grande Sertão: Veredas, Garbuglio (1972) considera a relevância da metáfora "travessia", palavra reiterada que fecha o 
romance, e que assume conotações várias, remetendo para a vida como "fluir". Ao tratar das águas do rio São Francisco e do rio Urucuia, ora claras, ora turvas, o crítico assevera que

\begin{abstract}
Não é apenas a transposição da preexistência para a existência com a aquisição das forças impulsionadoras que passam a comandar os atos do personagem/narrador, assinalando-o para tarefas excepcionais. É também a ideia de travessia, que, de notação concreta, passa a assumir conotações variadas até abranger todo o romance como grande e dominadora metáfora. (GARBUGLIO, 1972, p. 60).
\end{abstract}

Apontávamos, na proposta inicial deste artigo, para elementos intratextuais na obra de Rosa. Reconhecíamos fortes indícios, tais como ritos, símbolos e metáforas originais encontrados de modo similar em diferentes contos e que indicavam direções contrárias, encaminhando-nos para uma leitura em que a construção de novos sentidos e o desvendar de enigmas eram desafios propostos por um narrador, às vezes personagem/narrador, muito perspicaz. Com a crítica que Garbuglio empreende ao romance de Guimarães Rosa, consolida-se nossa referência feita à travessia como símbolo da viagem, ocasião de herói que têm os personagens em seus antipériplos em Tutameia Terceiras Estórias, com "a abertura do mundo", "o deslumbramento de iniciante", mas também com a passagem da "preexistência para a existência", "enquanto a vida é confirmação do destino" (GARBUGLIO, 1972, p. 65), conforme se observa na travessia do personagem Riobaldo.

\title{
3 Entre o carnal e o espiritual, a doçura da garapa e do mel - caminhos que se bifurcam na viagem de Doriano
}

Retomando a análise que diz respeito à intratextualidade na obra rosiana, estabelecemos relações entre diversos contos de Tutameia Terceiras Estórias; sugerimos a proposta para a retenção/protensão evocada pela criação poética "olhando para trás, em frente olhava" (p. 691). Não obstante constatar-se nessa expressão o caráter de dualidade, extensivo aos contos aqui analisados, dentre os pontos ainda enigmáticos que permanecem, um deles se nos apresenta acentuadamente obscuro: por que Doriano olhava à frente, justo quando se volta para trás? É possível que nessa 
reflexão atentemos para outra importante polarização de dualidade no conto, as duas musas com as quais se envolve o protagonista: Aquina e Bici.

Doriano encontrava-se dividido entre dois "amores contrários, que esperavam seu resolver" (p. 689), entre a "feiçosa Aquina, no sombreado, relembrada, xodó e chamego, uso vezo" e a "iazinha Bici, flor de rososo jardim, de brancura, palhacinho de lindeza, água em moringa" que moravam "rumo-a-rumo" (p. 690). Em outra passagem, deparamo-nos com a importante referência dicotômica - após uma citação de Aquina e de Bici, respectivamente: "E o Drujo, invejador, que essas, uma e outra, por garapa e mel, também cobiçava!" (p. 690).

É possível relacionar a doçura da garapa, extraída da cana que se nutre do chão, ao caráter carnal da feitiçosa Aquina; o dulçor do mel, produzido pelas abelhas que povoam os ares, à espiritualidade da celestial Bici. Não podemos deixar de mencionar que o nome Bici remete-nos a Bice (ARAÚJO, 2001, p. 265), apelido de Beatriz Portinari, a musa espiritual de Dante Alighieri ${ }^{4}$.

No entanto, no que concerne à dualidade, um elemento, em um primeiro momento, parece-nos fugir à regra5:

Tinha de travar plano; e o coração não concordava. Aquina, ociosa meretriz, na Caçapa, banda da mão direita. A Bici, moça para ser nôiva, à beira da lagoa Itãs, do lado do outro lado. Ele espontâneo gemeu, mediante pragalhão [...].

Mandou. Ir o Rulimão fosse, mão direita, à Aquina, à Caçapa, com dinheiro, o alforrio; quisesse, lá ficasse, os três tempos, por espalhar o bofe, dias e mais - e desmoderado brabo renhir qualquer vindico... [...]. Mas, empunhando arma contra quem intruso ali aparecesse, ir o Seistavado à Itãs, mão canhota, com sua palavra de homem: de que, em breve, ele Doriano, nas praxes, visitava a Bici moça e a mãe e pai, pelo pedido, finitivo." (p. 690-691).

\footnotetext{
${ }^{4} \mathrm{O}$ nome da mulher que rivaliza com Bici também parece estar carregado de significação. No conto que sucede "Sota e barla", "Tapiiraiauara", o narrador refere-se a Iô Isnar como "duro e mau como uma quina de mesa" (p. 693). Há ainda outra referência emblemática à quina em Tutameia. No conto "Curtamão", sétima narrativa, o narrador diz: "em três, reparto quina pontuda" (p. 551), o que pode representar uma referência à quina, às armas do brasão de Portugal, que aqui se soma à Aquina, "ociosa meretriz" (p. 690).

${ }^{5}$ Seria de se esperar que a celestial Bici estivesse à direita e a Aquina, carnal, terrena, à esquerda, segundo o modelo universal proposto pelos evangelhos: "E porá as ovelhas à sua direita, mas os bodes à sua esquerda. Então dirá o rei aos que estiverem à sua direita: Vinde benditos de meu pai, possuí por herança o reino que vos está preparado desde a fundação do mundo [...]. Então dirá também aos que estiverem à sua esquerda: Apartai-vos de mim, malditos, para o fogo eterno, preparado para o diabo e seus anjos [...]". (Mateus, 25; $33-41$ ).
} 
Cumpre verificarmos a natureza da trajetória do viajante Doriano:

Tão então, se isso dos outros receava, não era sinal de que devia somente continuar a seguir, por diante, aquela própria serra diretiva, como pelas apagadas linhas de um documento? Obedecendo a segredas coisas assim o espiritado da boiada - o balanceio. Vezes outras jornadas, o rumo do chão, gado e gente, nem tanto à várzea, nem tanto à serra. (p. 690-691)

Considerado o caráter diretivo da viagem, nem tanto à várzea, nem tanto à serra, associado à ideia da viagem marítima - que pode se dar sem o desvio das curvas podemos supor que Doriano tenha executado o traçado de uma reta. É importante lembrar que as musas do boiadeiro residiam banda a banda, no trecho final da "reta", já perto da fazenda Capiabas.

Dessa forma, percebe-se o mapa afetivo na viagem de Doriano grafado como uma cruz. 0 desenho proposto pela cruz, caminhos que se bifurcam na viagem íntima do protagonista, apresenta uma alternativa para resolução do enigma próprio da expressão "olhando para trás, em frente olhava", determinando uma mudança de perspectiva. Ao chegar à fazenda Capiabas, Doriano muda de posição. Antes ele era o homem que, na aridez do sertão, seguia com determinação o seu destino sem dele desviar os seus olhos, olhos que, para uma possível interpretação, pode-se dizer que repousam na representação da espiritualidade. Doriano, portanto, quando chega a seu destino e olha para trás, desvia-se da catábase do mito de Orfeu, segundo a qual olhar para trás significa transgressão de uma ordem. Agora a posição das musas inverte-se para Doriano - à sua esquerda, a feitiçosa Aquina, à sua mão direita, a branquinha flor Bici, "menos um gosto de se morder que um perfume de respirar" (p. 690), "Tendo a perfeita certeza" (p. 691).

Atingida a sua meta, instaura-se um itinerário em que o viajante pode olhar para o mundo, agora, na perspectiva do sagrado, em decorrência da passagem de uma préexistência para a existência, conforme análise de Garbuglio para Grande Sertão: Veredas. $\mathrm{Na}$ viagem a cavalo, feita por Doriano e também pelo personagem Ladislau, nas andanças do canoeiro Hetério, ou mesmo na caminhada que faz o guia-de-cego Prudencinhano, a palavra travessia, de "notação concreta" (GARBUGLIO, 1970, p. 60), abre-se para múltiplas interpretações. 
Como afirmamos ao introduzir este ensaio, Tutameia Terceiras Estórias traz no nome o significado de ninharia, quase-nada, mexinflório. De modo não menos insólito, o título de seu primeiro conto, "Antiperipleia”, lembra viagem de volta, ou o contrário de um grande périplo, de uma grande viagem. A obra convoca-nos, portanto, como leitores, para a dinâmica de ir e vir das narrativas, ao mesmo tempo em que contraria a leitura linear da obra, pois aquilo que aparentemente é nada, "ninharia”, "nonada”, passa a ser uma existência inteira.

\section{Referências}

ARAUJO, Heloisa Vilhena. As três graças. São Paulo: Mandarim, 2001.

BÍBLIA. Português. Bíblia sagrada. Tradução de João Ferreira de Almeida. Barueri: Sociedade Bíblica do Brasil, 1997.

CHEVALIER, Jean; GHEERBRANT, Alain. Dicionário de Símbolos. Mitos, sonhos, costumes, gestos, formas, figuras, cores, números. 9.ed. Rio de Janeiro: José Olympio, 1995.

GARBUGLIO, José Carlos. O mundo movente de Guimarães Rosa. São Paulo: Ática, 1972.

ROSA, João Guimarães. Tutameia Terceiras Estórias. In__: Ficção Completa. V. II. Rio de Janeiro: Nova Aguilar, 1994.

. Estas Estórias. In__: Ficção Completa. V. II. Rio de Janeiro: Nova Aguilar, 1994.

Ave Palavra. In__: Ficção Completa. V. II. Rio de Janeiro: Nova Aguilar, 1994.

Recebido em junho de 2014.

Aceito em setembro de 2014. 